\title{
Bloqueio de nervo ciático por via anterior e bloqueio “3 em 1" (Winnie) em paciente politraumatizado por perda de resistência
}

\author{
Instituto de Ortopedia e Traumatologia do Hospital das Clinicas, \\ Faculdade de Medicina da Universidade de São Paulo, São Paulo
}

INTRLDUÇÃa

As técnicas de bloqueio periférico no membro inferior apresentam como fator limitante o posicionamento do paciente. Entretanto, existe a possibilidade do uso da abordagem por via anterior nos pacientes com dificuldade de movimentação ou mudança de decúbito, como os politraumatizados.

RELATD DO CASD

Paciente masculino, 38 anos, $64 \mathrm{~kg}$, P3 (etilista, com TBC pulmonar ativa em tratamento há 10 dias, paralisia cerebral e deficiente auditivo), vítima de atropelamento há sete dias, com fratura de úmero esquerdo, fratura exposta de fêmur e joelho direito, e suspeita de lesão cervical. Exames laboratoriais normais. Abordagem cirúrgica desbridamento de ferimento infectado em joelho direito e região lateral de perna direita. Conduta anestésica com bloqueio do nervo ciático direito por via anterior e bloqueio " 3 em 1 ” do mesmo membro. Utilizou-se estimulador de nervo periférico e agulha A 100 para realização dos bloqueios, porém, como não se obteve resposta motora satisfatória com estímulo inferior a $0,70 \mathrm{~mA}$ em nenhum deles, optou-se pela técnica de perda de resistência para a localização das bainhas perivasculares, injetando-se $20 \mathrm{ml}$ de ropivacaína $0,75 \% \mathrm{em}$ cada bloqueio. O procedimento cirúrgico iniciou-se após 30 minutos, transcorrendo sem queixas do paciente. Após 50 minutos, o paciente foi encaminhado à sala de RPA, evoluindo sem intercorrências.

DISCUSSÃG

A combinação do bloqueio do nervo ciático e do " 3 em 1" é satisfatória para pacientes submetidos à cirurgia de membros inferiores, podendo ser técnica alternativa ao bloqueio do neuroeixo ou à anestesia geral.

REFERÊNCIAS

Beck GP. Anterior approach to sciatic nerve block. Anesthesiology. 1963;222-4

2. Winnie AP. The 3 in 1 is it really 3 in 1, or 2 in 1 ? Reg Anesth. 1992;17(3):176-9.

Endereço para correspondência:

Waldir Cunha Júnior

Rua Cayowaá, 560 - apto. 132

São Paulo (SP) - CEP 05018-000

E-mail: familiacunha@uol.com.br 